\title{
Experimental Methods to Enable High-Throughput Characterization of New Structural Materials
}

\author{
NILS ELLENDT (1) ${ }^{1,2,4}$ BRIGITTE CLAUSEN (1), ${ }^{1,2}$ \\ NICOLE MENSCHING (1), ${ }^{1,2}$ DANIEL MEYER (i), ${ }^{1,2}$ \\ CHRISTINA PLUMP (D) ${ }^{3}$ HEIKE SONNENBERG (D),${ }^{1,2}$ \\ MATTHIAS STEINBACHER @i], ${ }^{1,2}$ and ANASTASIYA TOENJES $\mathbb{1}^{1,2}$ \\ 1.-Faculty of Production Engineering, University of Bremen, Badgasteiner Straße 1, \\ 28359 Bremen, Germany. 2.-Leibniz Institute for Materials Engineering - IWT, \\ Badgasteiner Straße 3, 28359 Bremen, Germany. 3.-Faculty of Computer Science and \\ Mathematics, University of Bremen, Bibliothekstraße 5, 28359 Bremen, Germany. \\ 4.-e-mail: ellendt@iwt.uni-bremen.de
}

\begin{abstract}
Data-driven methods for developing new structural materials require large databases to identify new materials from known process routes, the resulting microstructures, and their properties. Due to the high number of parameters for such process chains, this can only be achieved with methods that allow high sample throughputs. This paper presents the experimental approach of the "Farbige Zustände" method through a case study. Our approach features a high-temperature drop-on-demand droplet generator to produce spherical micro-samples, which are then heat-treated and subjected to various shorttime characterizations, which yield a large number of physical, mechanical, technological, and electrochemical descriptors. In this work, we evaluate achievable throughput rates of this method resulting in material property descriptions per time unit. More than 6000 individual samples could be generated from different steels, heat-treated and characterized within 1 week. More than 90,000 descriptors were determined to specify the material profiles of the different alloys during this time. These descriptors are used to determine the material properties at macro-scale.
\end{abstract}

\section{INTRODUCTION}

The development of new structural materials requires many alloy variants, the investigation of adapted heat-treatment strategies, and various characterizations, e.g., classical tensile tests, hardness measurements, or even forming tests. These analytical methods provide the characteristic values, such as tensile strength, needed later in the application. The disadvantage of this conventional method is that each analysis method usually defines its own specimen geometry, so that the effort required for specimen fabrication increases considerably with each chosen characterization method. ${ }^{1}$ At the same time, this dramatically reduces the

(Received May 27, 2021; accepted September 1, 2021;

published online October 17, 2021) throughput of possible investigable variants. However, Springer and Raabe were able to achieve a throughput of 145 samples in $35 \mathrm{~h}$ for sample synthesis, thermal and mechanical treatment, as well as tensile and hardness tests. ${ }^{2}$

High throughput methods for structural materials are usually based on graded materials. Thin-film methods ${ }^{3-6}$ allow the rapid generation of entire ternary or quaternary phase diagrams on a substrate, which can quickly be scanned with specific test methods given knowledge of the local composition. A disadvantage of the extremely thin-film thickness of a few micrometers ${ }^{4,7,8}$ is that the characteristic microstructures of structural materials with all their constituents, such as phases, precipitates, grains, or grain boundaries, cannot be represented in all three spatial dimensions. However, thin-film techniques are valuable techniques 
for the mapping of phases or phase transformations. ${ }^{3,9}$ The mechanical characterization is limited to nano-indentation. ${ }^{5,6}$

For this reason, thin-film methods have been established for functional materials ${ }^{10,11}$ whose properties are mainly determined by their composition. Typical examples are searching for materials with specific magnetic ${ }^{6,11}$ or corrosion properties. ${ }^{4,8}$

Diffusion couples ${ }^{12-16}$ are graded samples, which offer a larger length scale in all three dimensions. However, composition grading within one sample limits the heat-treatment possibilities without changing local compositions due to diffusion. Nevertheless, the increased length scale allows the adjustment of microstructures similar to conventional samples, thus making this method suitable for screening relationships between composition, heat treatment, microstructure, and hardness. ${ }^{16}$ It has also been used to evaluate magnetic properties of novel functional materials. ${ }^{15}$

Recently, laser metal deposition processes with a dynamic blending of powder have been developed to synthesize graded high-throughput samples. $7,17,18$ Since the process is highly scalable, samples sizes can be easily varied to accord for characterization requirements. Such samples are well suited for accelerated evaluation of microstructures, occurring phases, and hardness measurements. It has also been shown that this sample type can also be used to obtain corrosion properties. ${ }^{\text {. }}$

While grading allows many compositions to fit in a single sample, this method has limitations regarding characterization techniques. Since compositions are only local, the characterization of only local properties, such as hardness, is possible for mechanical analysis. Each variation of heat treatment also requires a whole new graded sample, even if only specific compositions within the sample are of interest. A new approach, presented in Ref. 19, involves synthesizing individual samples with laser metal deposition, each having a distinct composition. Such libraries of individual samples allow more flexibility regarding heat treatment, but may also allow deformation of samples for mechanical characterization.

Our method "Farbige Zustände" ${ }^{20}$ involves spherical micro-samples with a size in the order of a millimeter in diameter. The volume allows the representation of a characteristic microstructure. Metallic samples can be generated quickly and in large quantities using a droplet generator ${ }^{21}$ with high reproducibility. ${ }^{22}$ The solidification of the generated metal drops in free fall thus results in spherical micro-samples whose microstructure does not show any preferred direction. ${ }^{23}$ These samples can undergo a specific heat treatment to tailor their microstructure and properties. ${ }^{24-26}$ Figure 1 shows such steel micro-samples compared to a flat tensile test sample, which has the same mass as 1300 micro-samples. This exemplary comparison shows that high-throughput methods can be more

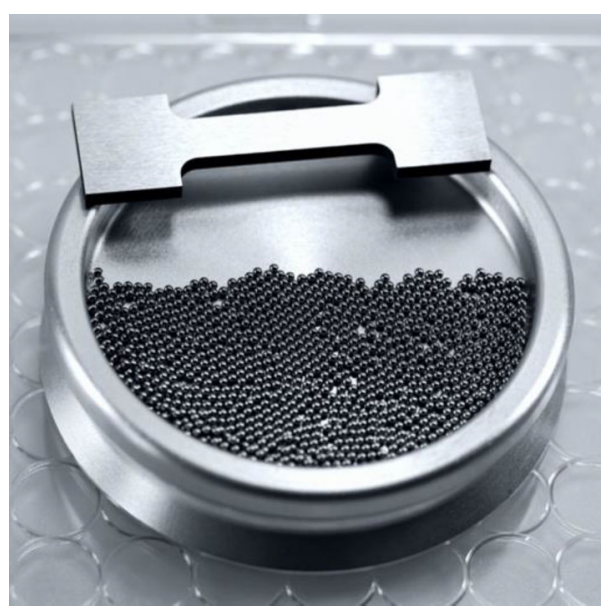

Fig 1. Comparison of spherical micro-samples (diameter $1 \mathrm{~mm}$ ) and a tensile sample, which has a mass of 1300 microsamples.

resource-efficient during the search for new materials. However, this sample form requires new characterization methods, which is a paradigm change in materials science. Whereas conventional methods determine the sample geometry depending on the test procedure, in this method, the sample defines possible test procedures. ${ }^{24}$ These test procedures do not result in conventional material properties such as tensile strength, but they will provide descriptors that can indicate changes in the desired properties or can even be mapped to those. ${ }^{27-29}$

In this work, we will present a process chain from synthesis to characterization. A case study, which we called "high-throughput week", was used to determine the maximal weekly sample throughput of the method. For this purpose, samples were characterized during 1 week under optimum conditions without any time restrictions. While detailed results from these compositions and heat treatments have been discussed in previous work, ${ }^{22}$ this work aims to question how much data for the subsequent informatics-enabled design of structural materials can be measured within 1 week.

\section{PROCESS CHAIN}

It is typical for high-throughput methods to characterize large numbers of samples in a variety of ways in a short time. For structural materials, the microstructure's adjustment plays a significant role. It is determined by the thermal history during the primary forming and heat treatment. Therefore, in addition to the actual characterization, these two process steps play a central role in a high-throughput process for structural materials. In the Farbige Zustände method, the process chain is divided into these three steps: synthesis, heat treatment, and characterization (Fig. 2). In the high-throughput cycle, these processes can be partially parallelized, since they take about the same amount of time. However, combined heat treatment of different material compositions can save time and resources. 


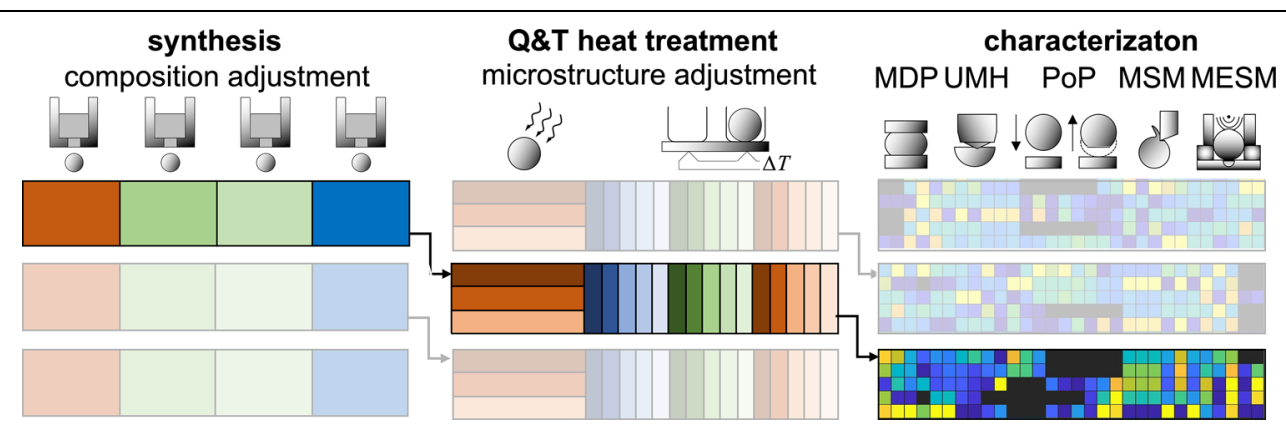

Fig 2. Process steps in a high-throughput method for structural materials: synthesis, heat treatment, and characterization. Process chains can run in parallel. See Table III and Ref. 24 for characterization methods.
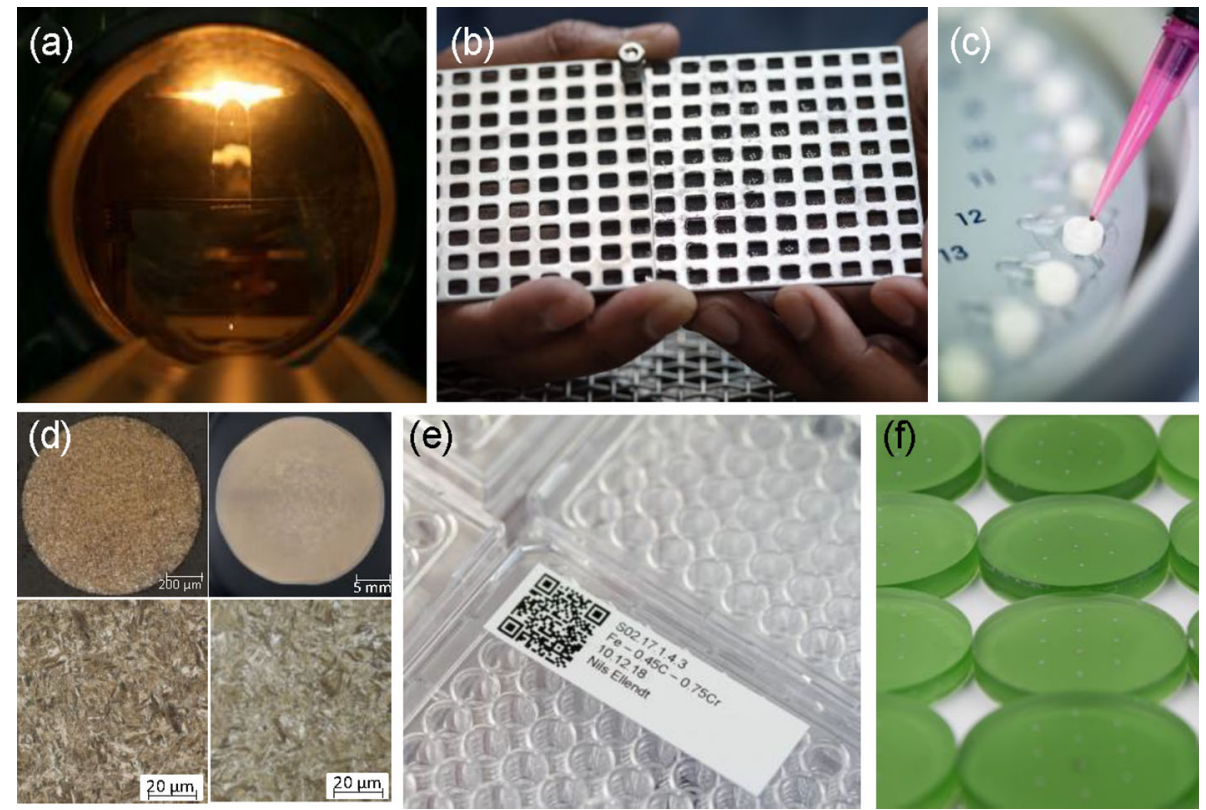

Fig 3. Synthesis, heat treatment and preparation process chain: (a) sample synthesis with a high-temperature droplet generator (sample diameter $900 \mu \mathrm{m}$ ), (b) batch-wise heat treatment in a furnace, (c) insertion of samples in DSC containers for fully automated heat treatment, (d) comparison of the microstructure of AISI 5140 heat-treated spheres and 20-mm rod, (e) samples in high-throughput container, (f) samples prepared as half-spheres.

Therefore, for our "high-throughput week" concept, these process steps were carried out one after the other. The focus of this work is on determining the sample throughput and presenting exemplary results.

\section{Synthesis}

The synthesis in the Farbige Zustände method is carried out employing a high-temperature droplet generator, ${ }^{21,22}$ with which metal melts can be reproducibly disintegrated into droplets of the same diameter (adjustable in the range of 300-2000 $\mu \mathrm{m}$ ) at temperatures of up to $1600^{\circ} \mathrm{C}$ (Fig. 3a). These droplets cool over a falling distance of $6.5 \mathrm{~m}$ in an inert gas atmosphere, and solidify before being collected in a liquid medium (quenching oil in the case of steel). ${ }^{23}$ Several thousand samples can thus be generated per experiment at a droplet frequency of $20 \mathrm{~Hz}$.
For the high-throughput week, five different types of steels were synthesized in the droplet generator. These include two novel Ni-modified variants of the X210Cr12 steel. Additionally, three additional steel alloys were bought as high-precision spheres. Steels investigated in this case study are summarized in Table I.

\section{Heat Treatment}

The samples were heat-treated in a batch container. Considering steels, the first step here is the collective austenitization of a batch in a furnace followed by quenching (Fig. 3b). Subsequently, the samples can either be tempered in a conventional furnace or be automatically annealed in a DSC with a sample changer (Fig. 3c). However, DSC is not only a heat-treatment process but also a short-time characterization technique for quantitative analysis of thermal stability of the microstructure and 
Table I. Alloy compositions examined during the "high-throughput week"

\begin{tabular}{lcc}
\hline Synthesis & Alloy & \multicolumn{1}{l}{$\begin{array}{l}\text { X2CrNiMo17-12-2 (AISI 316L), X210Cr12, (AISI D3) X210Cr12Ni2, X210Cr12Ni4, 41Cr4 } \\
\text { (AISI 5140) }\end{array}$} \\
$\begin{array}{l}\text { Commercially produced from } \\
\text { wire }\end{array}$ & X5CrNi18-10 (AISI 304), X5CrNiMo-17-12-2 (AIS 316), X46Cr13 (AISI 420)
\end{tabular}

Table II. Exemplary heat treatments used in this work

\section{Heat treatments}

Quenched in oil after solidification

$30 \mathrm{~K} / \mathrm{min} 950^{\circ} \mathrm{C} 1 \mathrm{~h} / 6$ bar $\mathrm{N} 2 / 180^{\circ} \mathrm{C}$ (air)

$30 \mathrm{~K} / \mathrm{min} 950^{\circ} \mathrm{C} 1 \mathrm{~h} / 6$ bar $\mathrm{N} 2 / 580^{\circ} \mathrm{C}\left(\mathrm{N}_{2}\right)$

\begin{tabular}{c} 
Abbreviation \\
\hline DoD \\
Q3T1 \\
Q3T5
\end{tabular}

precipitation behavior. ${ }^{28,30}$ Figure $3 \mathrm{~d}$ compares the microstructure of a heat-treated spherical microsample to a conventionally produced and heattreated rod (diameter $20 \mathrm{~mm}$ ), both made of $41 \mathrm{Cr} 4$ (AISI 5140). While the substantial deformation of structural materials in the process chain refines the microstructure, the drop-on-demand process achieves a similar size scale of the prior austenite grain size and derived martensite needle structure due to the increased cooling rate. The result shows that heat-treatment conditions are transferable between the micro -and the macro-scale.

In this work, we will focus on exemplary results of $\mathrm{X} 210 \mathrm{Cr} 12 \mathrm{NiX}$ alloys with $\mathrm{X}=0,2,4$ mass\%. These alloys were analyzed once in their initial condition after being quenched directly after droplet solidification in oil. Two further heat treatments named Q3T1 and Q3T5 (Table II) were performed in a conventional vacuum furnace using specific batching equipment capable of carrying the spheres (Fig. $3 \mathrm{~b}$ ). The samples were heated at low pressure $\left(\sim 5 \times 10^{-2}\right.$ mbar $)$ to $950^{\circ} \mathrm{C}$ at a heating rate of $30 \mathrm{~K} / \mathrm{s}$, held for at least $1 \mathrm{~h}$ and subsequently quenched with agitated nitrogen at a pressure of 6 bars. In a second step, the Q3T1 samples were tempered at a temperature of $180^{\circ} \mathrm{C}$ for $2 \mathrm{~h}$ in air, while the Q3T5 were tempered at a temperature of $580^{\circ} \mathrm{C}$ for $2 \mathrm{~h}$ in nitrogen atmosphere. Table II summarizes these heat treatments.

\section{Sample Preparation}

For high-throughput analyses, methods are preferred for short-time characterizations in which the spheres can be used without further preparation. This concerns, for example, the application of mechanical deformation. In this case, samples were stored in high-throughput containers (Fig. 3e). However, nano-indentation, for example, requires a flat, polished surface so that the sample must be metallographically prepared by embedding, grinding, and polishing (Fig. 3f). Thus, samples are hemispherically divided. ${ }^{24}$ Such preparation also allows the use of XRD and micromagnetic analysis.

\section{Characterization}

The samples' characterization is partly performed by conventional methods such as DSC or, after embedding, by XRD or nano-indentation. However, the DSC measurements were performed with nonequilibrium heating rates to perform the measurements faster. In addition, numerous new methods have been developed (Table III) that can work directly with spherical micro-specimens: these include micro-compression testing (compression test) and particle-oriented peening (deformation from fast impact). In this work, we will show exemplary results from the aforementioned two novel high-throughput characterization methods, which involve a specific sample deformation. These results each represent the mean values from 10 analyzed particles.

\section{Micro-compression Testing}

The micro-compression test ${ }^{31,35}$ depicts a classic compression test on spherical micro-samples. For this purpose, a miniaturized pressure unit is used to compress a spherical micro-sample with a defined force while continuously measuring the displacement. From the resulting force-displacement curves, the mechanical work, $W_{\mathrm{t}}$, can be determined independent of the loading, serves as a descriptor for the elastic-plastic deformation behavior (Fig. 4).

For the maximum loading, it can be divided into an elastic $\left(W_{\mathrm{el}}\right)$ and a plastic part $\left(W_{\mathrm{pl}}\right)$ since the unloading of the sample is also recorded. The descriptor, $\eta$, describes the elastic deformation part since it is the quotient of total and the elastic mechanical work. In addition to the force-displacement diagram, the equivalent stress-strain relationship is calculated by taking the sample geometry into account (Fig. 4). Assuming pure plastic deformation behavior, the area of a circle segment as a function of the current displacement, $x$, is calculated and used as a reference area for converting the force, $F$, to an equivalent stress, $\sigma_{\text {eq }}$. Equivalent stress descriptors at a defined 
Table III. Summary of short-time characterizations

\begin{tabular}{|c|c|c|}
\hline Abbreviation & Method [reference] & Number of descriptors \\
\hline DSC & Differential scanning calorimetry ${ }^{28}$ & 5 \\
\hline EchC & Electrochemical characterization ${ }^{22}$ & 9 \\
\hline LiSE & Laser-induced shockwave indentation ${ }^{27}$ & 6 \\
\hline MaPD & Dilatometry ${ }^{30}$ & 4 \\
\hline MDP & Micro-compression test ${ }^{31}$ & 10 \\
\hline MESM & Micro-extrusion strain measurement ${ }^{32}$ & 3 \\
\hline MM & Micro-magnetic characterization ${ }^{24}$ & 16 \\
\hline MSM & Micro-sample machining ${ }^{33}$ & 4 \\
\hline $\mathrm{PoP}$ & Particle-oriented peening ${ }^{34}$ & 6 \\
\hline UMH & Universal micro-hardness measurement ${ }^{29}$ & 7 \\
\hline $\mathrm{XRD}$ & X-ray diffraction ${ }^{24}$ & 20 \\
\hline
\end{tabular}
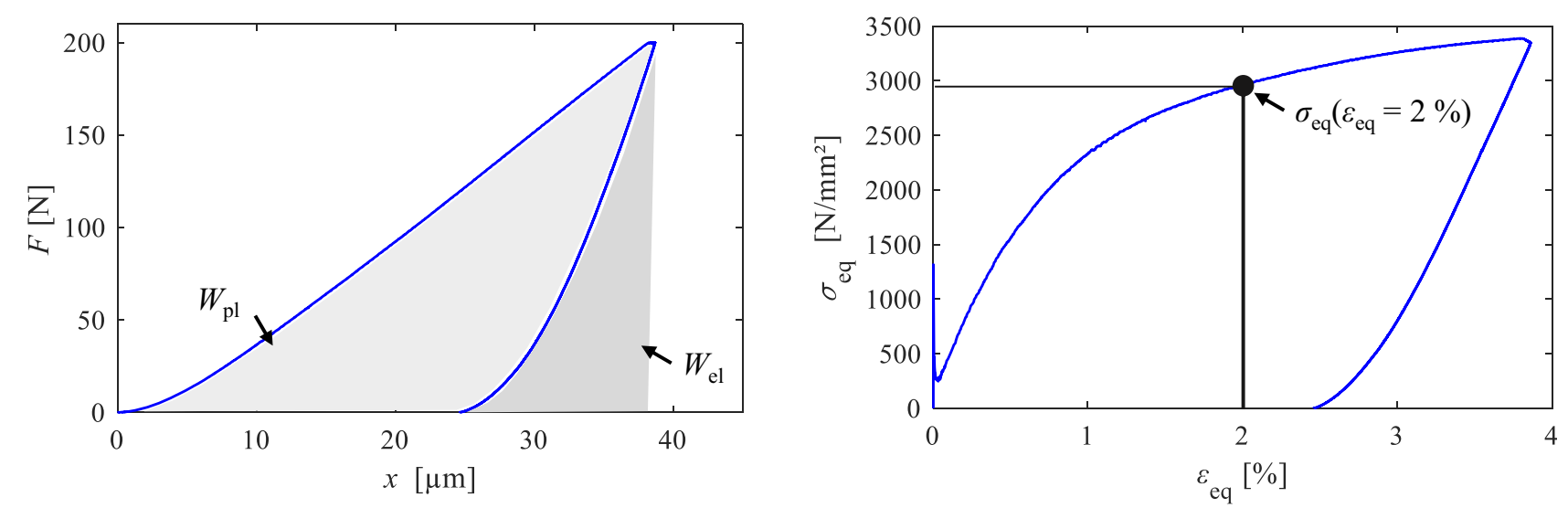

Fig 4. Exemplary force-displacement and equivalent stress-strain curves of the micro-compression test on X210Cr12-Q3T5 with an initial diameter of $1002 \mu \mathrm{m}$.

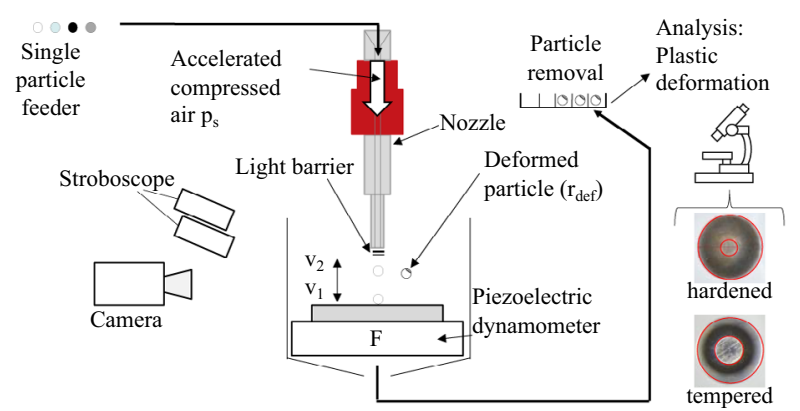

Fig 5. Schematic process sequence of particle-oriented peeing method.

compression are used as normalized values for the comparison of samples with different initial diameters. $^{31}$

\section{Particle-Oriented Peening}

In particle-oriented peening, ${ }^{24,34,36}$ a single spherical micro-sample is accelerated to impact on a hardened contact plate using compressed air (Fig. 5). Based on deceleration and deformation effects, information about the materials' behavior at high strain rates can be determined. Figure 5 schematically visualizes the process sequence from sample introduction to sample analysis. During the process, the sample movement is accessed using a system of two stroboscopes and a camera, triggered by a light barrier, allowing the determination of the sample velocity before and after the impact. The decrease in velocity is a measure of the energy introduced into the plastic deformation of the sample. The plastic deformation itself can be measured after impact using a light microscope. ${ }^{25}$

\section{RESULTS}

\section{High-Throughput Rates}

During 1 week, we were able to characterize 6000 samples, including repeated measurements. Figure 6 shows characterized samples per day for each characterization method and the number of descriptors determined by the method. For example, 480 samples could be characterized by particle-oriented peening with six descriptors each. On the other hand, a micro-compression test could characterize 120 samples per day but could determine ten descriptors per sample. Thus, different 


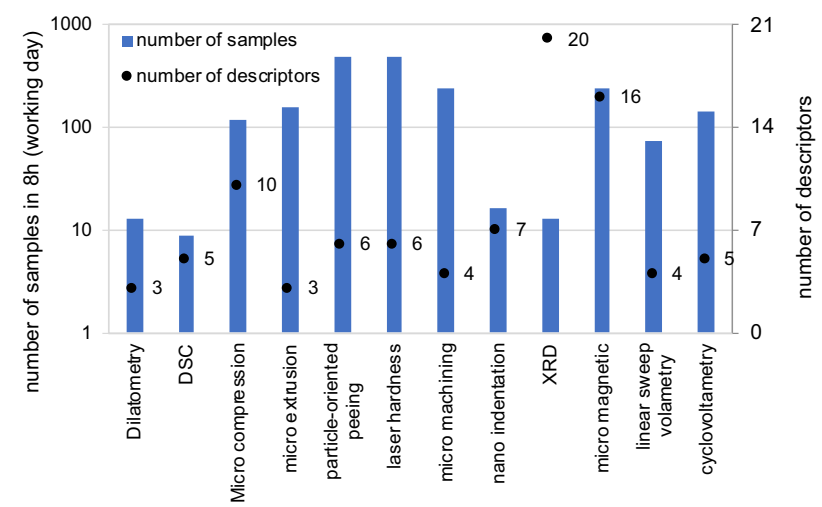

Fig 6. Achieved sample rates in $8 \mathrm{~h}$ (working day) and descriptors determined with each characterization.

characterization methods have different information densities and different throughputs. Usually, fast methods have a lower information density compared to slow methods. For instance, an XRD could only characterize 13 samples per day, but up to 20 descriptors each for fractions of the different phases and more. A total number of 95,840 descriptors was determined within 1 week. Steinbacher et al. published detailed information on the individual characterization methods in Ref. 24.

These throughputs are much higher than those reported by Springer and Raabe, ${ }^{2}$ who were able to perform synthesis, mechanical, and thermal treatments, as well as tensile and hardness tests, of 145 samples in $35 \mathrm{~h}$. Furthermore, a major disadvantage of their method is the macro-scale of the samples, which limits the throughput. If further analysis methods need to be included, the effort for additional samples will dramatically increase compared to the synthesis of additional samples with the drop-on-demand method.

Figure 7 shows a heatmap of descriptors determined within the high-throughput week for the different compositions (cf. Table I) and heat treatments. During 1 week, eight different types of steel in various heat-treatment conditions were characterized regarding their mechanical and physical properties, which resulted in a widespread description. Descriptors further referred in this paper to are additionally marked at the top of the heatmap.

As an excerpt from the manifold results of the high-throughput week, descriptors determined for the alloys X210Cr12, X210Cr12Ni2, and X210Cr12Ni4 with MDP and PoP are exemplarily discussed. In Fig. 8, heatmaps presenting the results of the micro-compression test (Fig. $8 \mathrm{a}, \mathrm{b}$, and c) and the particle-oriented peening (Fig. 8d) are displayed.

Regarding the micro-compression test, we chose three descriptors. The mechanical work, $\mathrm{W}_{t}$ $(F=195 \mathrm{~N})$, determined at a loading of $195 \mathrm{~N}$, and the elastic deformation part, $\eta$, determined at maximum loading of $F_{\max }=200 \mathrm{~N}$ are derived from force-displacement curves (Fig. 8a and b). The mechanical work is highest for the DoD material states showing the smallest elastic deformation behavior. The highest values of the elastic deformation part are reached for the Q3T1 states of $\mathrm{X} 210 \mathrm{Cr} 12$ and $\mathrm{X} 210 \mathrm{Cr} 12 \mathrm{Ni} 2$, also resulting in the lowest mechanical work, $\mathrm{W}_{t}(F=195 \mathrm{~N})$. For the same heat treatment, a further increase of Nicontent (X210Cr12Ni4-Q3T1) leads to a drop in both descriptor values. A similar color trend can be obtained by investigating the normalized stressdescriptor, $\sigma_{\text {eq }}$, determined at a compression of $\varepsilon_{\mathrm{eq}}=2 \%$ from equivalent stress-strain curves (Fig. 8c). However, differences between material states are more clearly visible.

The particle-oriented peening method results in a descriptor for the plastic deformation based on the rebound and impact velocity ratio, $\mathrm{v}_{2} / \mathrm{v}_{1}$. During impact, elasto-plastic deformation of the sample takes place. During rebound, stored elastic energy is released. Thus, a small rebound velocity indicates a higher plastic deformation and results in a lower ratio (cf., e.g., Refs. ${ }^{37,38}$ ). Consequently, as shown in the heatmap in Fig. 8d, the material states considered in this work suggest a more plastic behavior of the DoD states. While the material states annealed at low temperature (Q3T1) show only slightly higher ratios at 4 mass $\% \mathrm{Ni}$, ratios higher than 0.6 indicate low plastic deformation for X210Cr12 and $\mathrm{X} 210 \mathrm{Cr} 12 \mathrm{Ni2}$. This trend is reversed for the higher annealing temperature.

The descriptors show low standard deviations (Fig. 8e, f, g, and h). The majority of MDP descriptors have a standard deviation of $<5 \%$ and those of PoP even $<2 \%$. This indicates a high reproducibility of descriptor determination.

The combination of descriptors determined by different testing methods is a promising approach for material characterization. Analyzing descriptor values from $\mathrm{MDP}$ and $\mathrm{PoP}$, we can see that they react to properties that do not necessarily change from material state to material state. The heatmap in Fig. 8a shows that MDP- $\eta$ detects no difference between $\mathrm{X} 210 \mathrm{Cr} 12$ and $\mathrm{X} 210 \mathrm{Cr} 12 \mathrm{Ni} 2$ for the heat treatments of DoD and Q3T5. However, it detects differences for both alloys when they underwent heat treatment Q3T1. We see the opposite picture in Fig. 8d for the velocity ratio from PoP: The descriptor, $v_{2} / v_{1}$, shows a difference between $\mathrm{X} 210 \mathrm{Cr} 12$ and $\mathrm{X} 210 \mathrm{CrNi2}$ for heat treatments Q3T5 and DoD, but none for heat treatment Q3T1. That is, given a particular descriptor's result, a distinction of states is not always possible. However, combining the information that both descriptors provide, we were able to construct three descriptors sensitive to the increase of nickel ( 0 mass $\%$ to 2 mass\%). These descriptors are the ratio (inverse ratio, respectively) between $\eta$ and $v_{2} / v_{1}$ (Fig. $8 \mathbf{i}$ and j), representing the angular position in a two-dimensional coordinate system, and the sum of squares of $\eta$ and $v_{2} / v_{1}$ (Fig. 8k), representing the squared distance to the origin. Heatmaps in Fig. $8 \mathrm{i}$ and $\mathrm{j}$ show that we can 


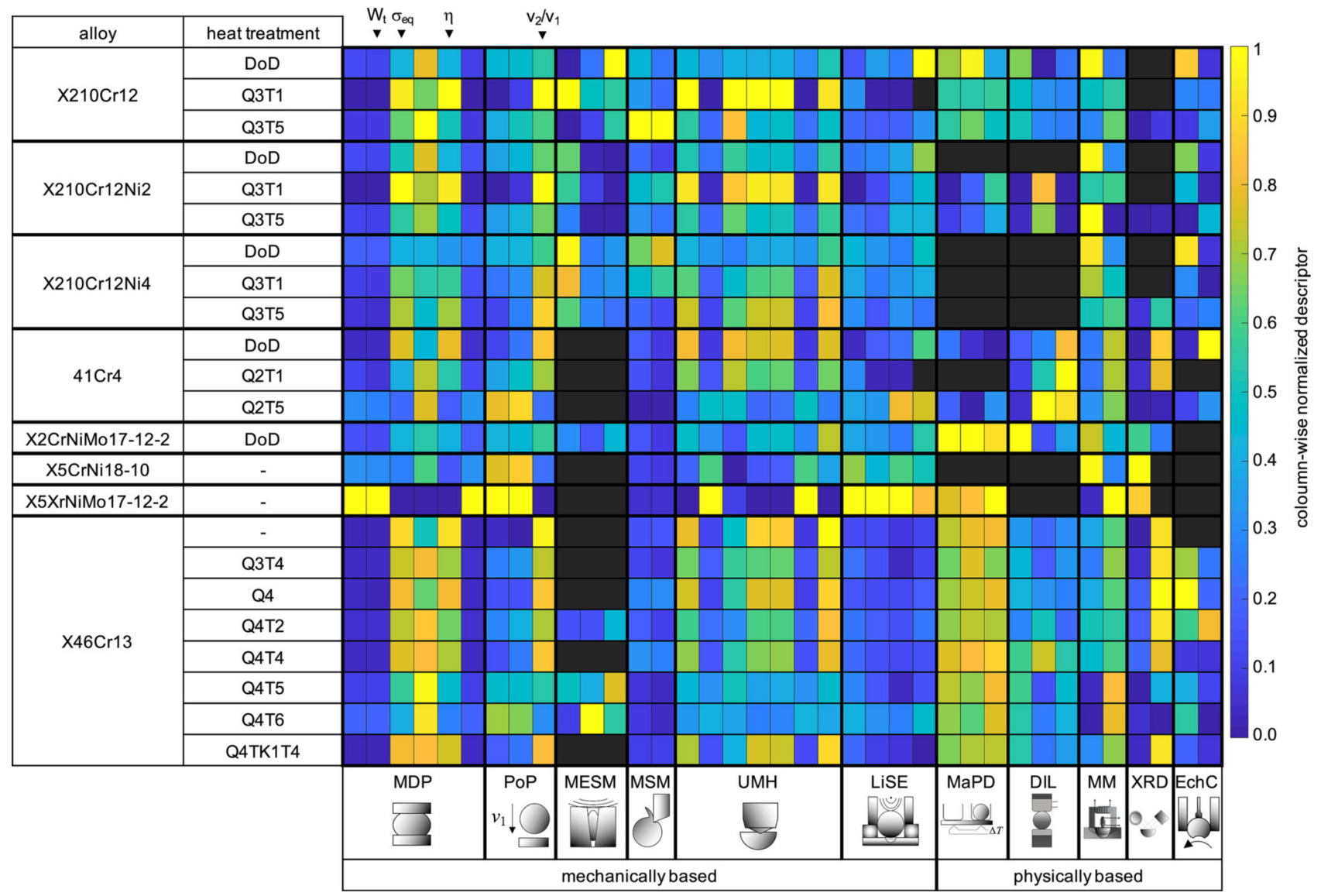

Fig 7. Heatmap of descriptors determined during the high-throughput week (MDP micro-compression test, $P o P$ particle-oriented peening; for the other abbreviations, see Table III). Black color indicates values not measured either due to limitations of the method or due to the set time frame (Color figure online).

now identify all six states ( $0 \%$ and $2 \%$ of nickel) utilizing the descriptor's value. Calculating the relative minimal distance for the two given descriptors and the calculated ones additionally verifies this finding. If this distance is small, there are at least two states that look alike for this descriptor. The higher the distance, the better the differentiation between states for the given descriptor.

\section{CONCLUSION}

In this work, we have presented the experimental sequence of a high-throughput method for structural materials. By combining sample synthesis with a single droplet generator with a two-stage heat treatment, we are able to tailor specific microstructures in individual samples. These samples can be characterized in various ways using conventional and newly developed methods, including actual deformation processes. We have exemplarily shown that, with these descriptors and their combinations, material states of composition and heat treatment can clearly be distinguished and characterized with respect to their mechanical properties.

Within 1 week, 6000 samples could be characterized using a spectrum of short-time characterizations, which provided more than 90,000 descriptors on physically- and mechanically-based properties of the samples and their microstructural states. A greatly accelerated search for new materials with data-based methods is thus made possible.

The 6000 micro-samples have about the mass of five small flat tensile samples. While the microsample analyses included several repetitive measurements to ensure reproducibility, five tensile samples are hardly sufficient to characterize only a single material condition. High-throughput methods are not only faster than conventional methods for materials development but they are also much more resource-efficient. This efficiency allows the trying of even alloying concepts, which may include costly elements, or, on the other hand, trying a large 


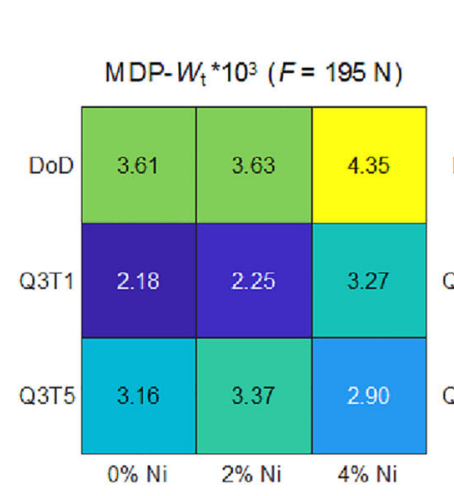

(a)

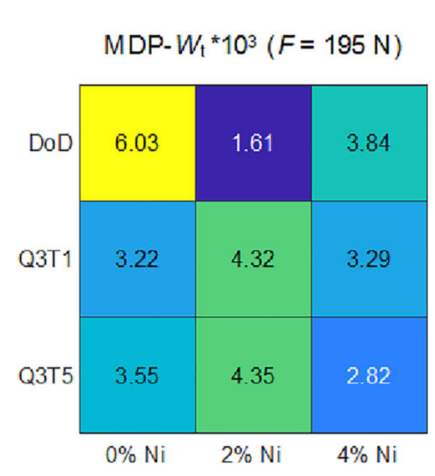

(e)

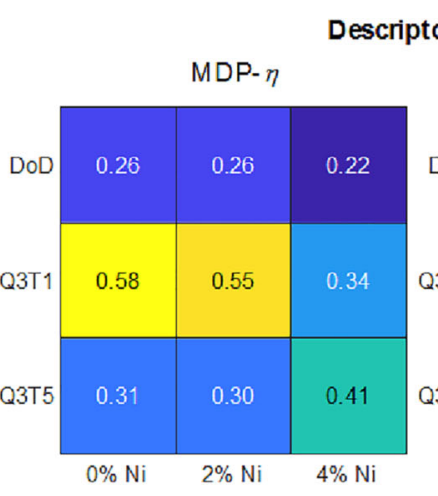

(b)

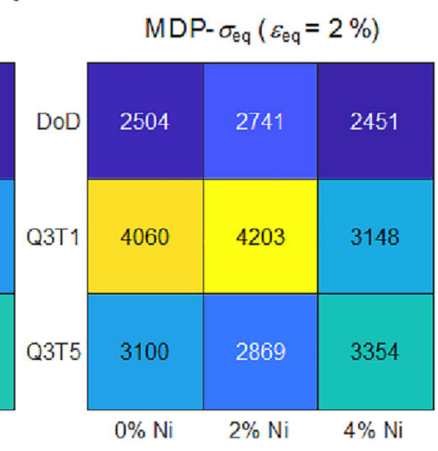

(c)

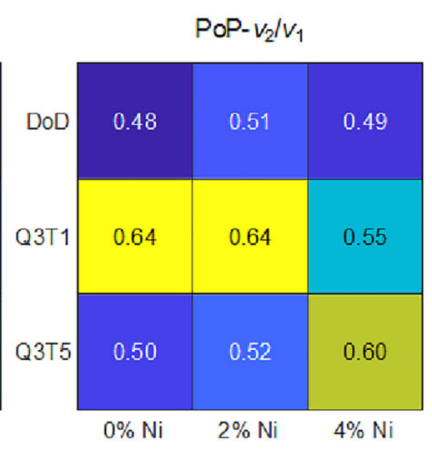

(d)

relative standard deviation $/ \%$

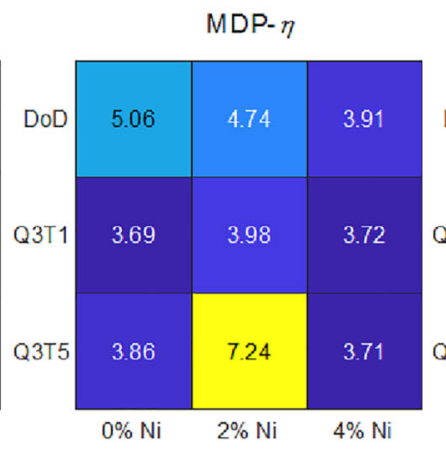

(f)

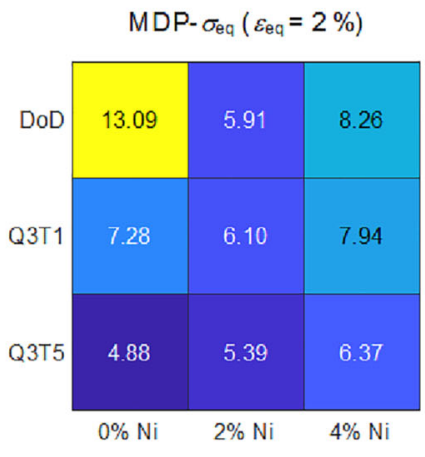

(g)

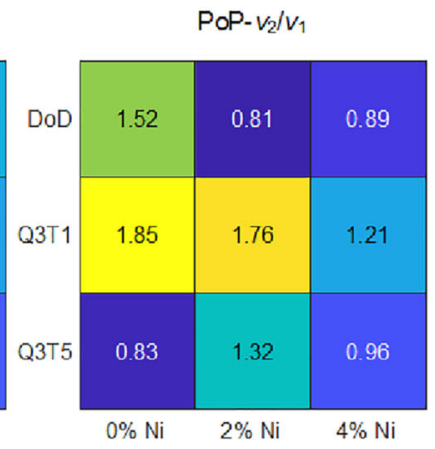

(h)

Descriptor combination

$\theta$

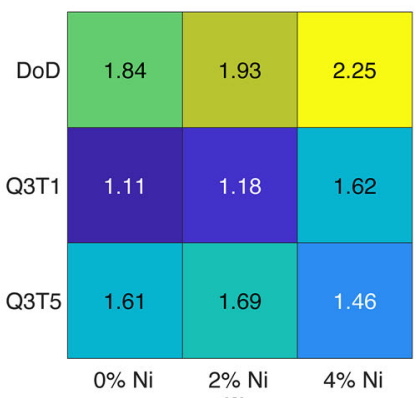

(i) $\theta^{-1}$

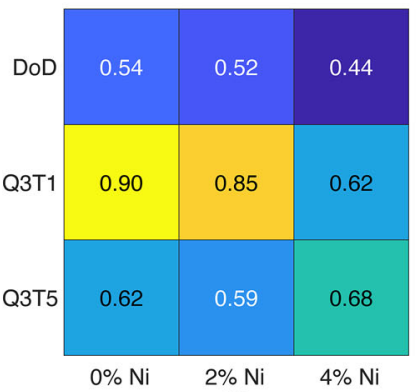

(j)

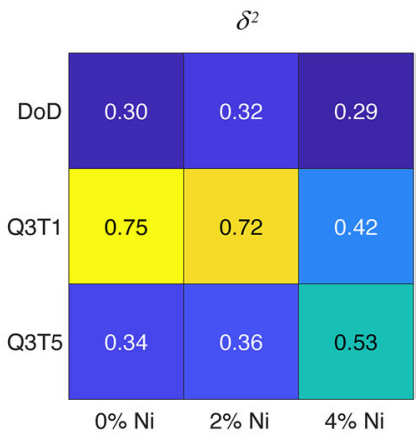

(k)

Fig 8. Heatmaps, descriptors for $\mathrm{X} 210 \mathrm{Cr} 12, \mathrm{X} 210 \mathrm{Cr} 12 \mathrm{Ni} 2$, and $\mathrm{X} 210 \mathrm{Cr} 12 \mathrm{Ni} 4$ with different heat treatments: (a) mechanical work $W_{\mathrm{t}}(F=195 \mathrm{~N})$, (b) elastic deformation part $\eta$, (c) stress-descriptor $\sigma_{\text {eq }}\left(\varepsilon_{\text {eq }}=2 \%\right.$ ), all from MDP, and (d) velocity ratio $v_{2} / v_{1}$ from PoP and their standard deviation in \%, (e-h) combination of descriptors MPD- $\eta$ and PoP- $v_{2} / v_{1}$ for X210Cr12, X210Cr12Ni2, and X210Cr12Ni4 with different heat treatments, (i) their ratio $\theta$, (j) inverse ratio $\theta^{-1}$, and $(\mathrm{k})$ their distance $\delta^{2}=\eta^{2}+\left(v_{2} / v_{1}\right)^{2}$

number of lean alloying concepts which eliminate expensive elements or compensate for contamination from recycling by adjusted compositions.

\section{ACKNOWLEDGEMENTS}

This research is funded by Deutsche Forschungsgemeinschaft (DFG, German Research Foundation)_Project Number 276397488_SFB 1232 and the support is gratefully acknowledged. The authors would like to thank Jan Rathke for taking photos Figs. 1 and 3c, e and f.

\section{FUNDING}

Open Access funding enabled and organized by Projekt DEAL.

\section{CONFLICT OF INTEREST}

On behalf of all authors, the corresponding author states that there is no conflict of interest.

\section{OPEN ACCESS}

This article is licensed under a Creative Commons Attribution 4.0 International License, which per- 
mits use, sharing, adaptation, distribution and reproduction in any medium or format, as long as you give appropriate credit to the original author(s) and the source, provide a link to the Creative Commons licence, and indicate if changes were made. The images or other third party material in this article are included in the article's Creative Commons licence, unless indicated otherwise in a credit line to the material. If material is not included in the article's Creative Commons licence and your intended use is not permitted by statutory regulation or exceeds the permitted use, you will need to obtain permission directly from the copyright holder. To view a copy of this licence, visit http://creativecommons.org/licenses/by/4.0/.

\section{REFERENCES}

1. X. Zhang and Y. Xiang, J. Materiomics 3, 3. (2017).

2. H. Springer and D. Raabe, Acta Mater. 60, 12. (2012).

3. N.M. Al Hasan, H. Hou, T. Gao, J. Counsell, S. Sarker, S. Thienhaus, E. Walton, P. Decker, A. Mehta, A. Ludwig, and I. Takeuchi, ACS Comb. Sci 22, 11. (2020).

4. T.A. Aljohani and B.E. Hayden, Electrochim. Acta 111, 930. (2013).

5. D. Naujoks, M. Schneider, S. Salomon, J. Pfetzing-Micklich, A.P.A. Subramanyam, T. Hammerschmidt, R. Drautz, J. Frenzel, A. Kostka, G. Eggeler, G. Laplanche, and A. Ludwig, ACS Comb. Sci. 22, 5. (2020).

6. S. Salomon, S. Hamann, P. Decker, A. Savan, L. Meshi, and A. Ludwig, Phys. Status Solidi A 212(9), 1969. (2015).

7. J. Nie, L. Wei, D.-1 Li, L. Zhao, Y. Jiang, and Q. Li, Addit. Manuf. 35, 101295. (2020).

8. Y. Shi, B. Yang, P.D. Rack, S. Guo, P.K. Liaw, and Y. Zhao, Mater. Des. 195, 109018. (2020).

9. N.M. Al Hasan, H. Hou, S. Sarkar, S. Thienhaus, A. Mehta, A. Ludwig, and I. Takeuchi, Engineering 6, 6. (2020).

10. M. Otani, K. Itaka, W. Wong-Ng, P. Schenck, and H. Koinuma, Appl. Surf. Sci. 254, 3. (2007).

11. J.R. Hattrick-Simpers, C. Jun, M. Murakami, A. Orozco, L. Knauss, R.J. Booth, E.W. Greve, S.E. Lofland, M. Wuttig, and I. Takeuchi, Appl. Surf. Sci. 254, 3. (2007).

12. J.-C. Zhao, Annu. Rev. Mater. Res. 35, 51. (2005).

13. J.-C. Zhao, Prog. Mater. Sci. 51, 5. (2006).

14. J.-C. Zhao, X. Zheng, and D.G. Cahill, JOM 63, 3. (2011).

15. D. Goll, R. Loeffler, J. Herbst, R. Karimi, and G. Schneider, J. Phys. Condens. Matter 26, 6. (2014).

16. J. Wang, G. Xu, X. Zeng, J. Llorca, and Y. Cui, Mater. Des. 197, 109243. (2021).

17. H. Dobbelstein, E.P. George, E.L. Gurevich, A. Kostka, A Ostendorf, and G. Laplanche, Int. J. Extreme Manuf. 3, 1. (2021).
18. M. Kuczyk, L. Kotte, J. Kaspar, M. Zimmermann, and C. Leyens, Front. Mater. 7, 242. (2020).

19. M. Moorehead, K. Bertsch, M. Niezgoda, C. Parkin, M. Elbakhshwan, K. Sridharan, C. Zhang, D. Thoma, and A. Couet, Mater. Des. 187, 108358. (2020).

20. N. Ellendt and L. Madler, J. Heat Treat. Mater. 73, 1. (2018).

21. S.I. Moqadam, L. Madler, and N. Ellendt, Micromachines 10, 7. (2019).

22. S.I. Imani Moqadam, M. Baune, I. Bösing, C. Heinzel, D. Meyer, A. Thomann, N. Wielki, and N. Ellendt, Metals 10(3), 297. (2020).

23. S.I. Moqadam, L. Madler, and N. Ellendt, Materials 12, 22. (2019).

24. M. Steinbacher, G. Alexe, M. Baune, I. Bobrov, I. Bosing, B. Clausen, T. Czotscher, J. Epp, A. Fischer, L. Langstadtler, D. Meyer, S. Raj Menon, O. Riemer, H. Sonnenberg, A. Thomann, A. Toenjes, F. Vollertsen, N. Wielki, and N. Ellendt, High-Throughput 8, 4. (2019).

25. N. Wielki, M. Steinbacher, and D. Meyer, Materials 13(4), 904. (2020)

26. I. Bösing, L. Cramer, M. Steinbacher, H.W. Zoch, J. Thöming, and M. Baune, AIP Adv. 9(6), 065317. (2019).

27. T. Czotscher, A. von Hehl, T. Radel, and A. Toenjes, Proc. Manuf. 47, 756. (2020).

28. A. Toenjes, H. Sonnenberg, C. Plump, R. Drechsler, and A. von Hehl, Metals 9, 2. (2019).

29. S. Huhn, H. Sonnenberg, S. Eggersglüß, B. Clausen, and R. Drechsler, Proc. IEEE Symp. Ser. Comp. Intell. (SSCI), 2017, 1 .

30. L. Cramer, A. Toenjes, M. Steinbacher, A. von Hehl, and H.W. Zoch, Adv. Eng. Mater. 21, 1800100. (2018).

31. H. Sonnenberg and B. Clausen, Materials 13(3), 733. (2020).

32. G.A.D. Stöbener, L. Langstädtler, M. Herrmann, C. Schenck, and A. Fischer, Proc. 5th CIRP Conf. Surf. Integ., Vitoria-Gasteiz, 2020, 6.

33. A. Beinhauer, C. Heinzel, and O. Riemer, Proc. 6th Int. Conf. nanoManuf. (nanoMan) (2018).

34. J. Kämmler, N. Wielki, N. Guba, N. Ellendt, and D. Meyer, Materialwiss. Werkstofftech. 50(1), 5. (2019).

35. H. Sonnenberg and B. Clausen, Proc. Inst. Mech. Eng. Part L 235(6), 1226. (2021).

36. N. Wielki, H. Sonnenberg, D. Meyer, and B. Clausen, J. Mater. Process. Technol. 289, 116960. (2021).

37. M. Hassani-Gangaraj, D. Veysset, K.A. Nelson, and C.A. Schuh, Nat. Commun. 9, 1. (2018).

38. Q. Chen, A. Alizadeh, W. Xie, X. Wang, V. Champagne, A. Gouldstone, J.-H. Lee, and S. Müftü, J. Therm. Spray Technol. 27, 4. (2018).

Publisher's Note Springer Nature remains neutral with regard to jurisdictional claims in published maps and institutional affiliations. 